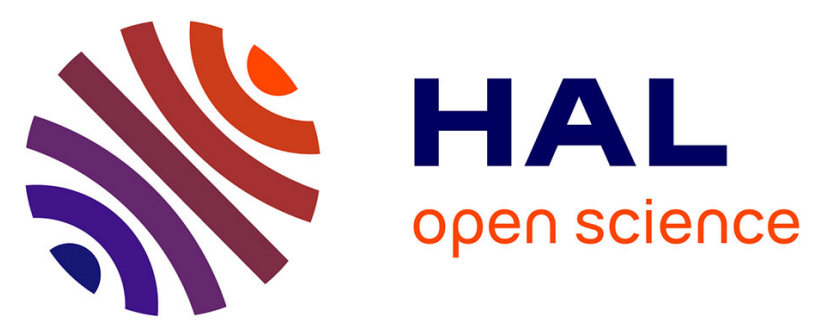

\title{
AGrav - the New International Absolute Gravity Database of BGI and BKG and its Benefit for the Global Geodynamics Project (GGP)
}

H. Wilmes, H. Wziontek, R. Falk, S. Bonvalot

\section{- To cite this version:}

H. Wilmes, H. Wziontek, R. Falk, S. Bonvalot. AGrav - the New International Absolute Gravity Database of BGI and BKG and its Benefit for the Global Geodynamics Project (GGP). Journal of Geodynamics, 2009, 48 (3-5), pp.305. 10.1016/j.jog.2009.09.035 . hal-00594418

\author{
HAL Id: hal-00594418 \\ https://hal.science/hal-00594418
}

Submitted on 20 May 2011

HAL is a multi-disciplinary open access archive for the deposit and dissemination of scientific research documents, whether they are published or not. The documents may come from teaching and research institutions in France or abroad, or from public or private research centers.
L'archive ouverte pluridisciplinaire HAL, est destinée au dépôt et à la diffusion de documents scientifiques de niveau recherche, publiés ou non, émanant des établissements d'enseignement et de recherche français ou étrangers, des laboratoires publics ou privés. 


\section{Accepted Manuscript}

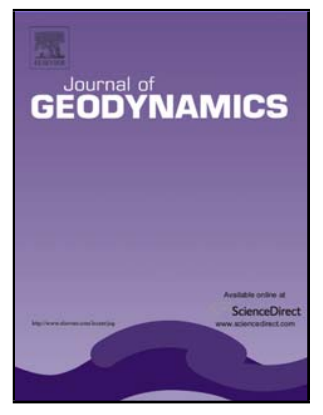

Title: AGrav - the New International Absolute Gravity Database of BGI and BKG and its Benefit for the Global Geodynamics Project (GGP)

Authors: H. Wilmes, H. Wziontek, R. Falk, S. Bonvalot

PII:

S0264-3707(09)00102-1

DOI: doi:10.1016/j.jog.2009.09.035

Reference: GEOD 929

To appear in: $\quad$ Journal of Geodynamics

Please cite this article as: Wilmes, H., Wziontek, H., Falk, R., Bonvalot, S., AGrav - the New International Absolute Gravity Database of BGI and BKG and its Benefit for the Global Geodynamics Project (GGP), Journal of Geodynamics (2008), doi:10.1016/j.jog.2009.09.035

This is a PDF file of an unedited manuscript that has been accepted for publication. As a service to our customers we are providing this early version of the manuscript. The manuscript will undergo copyediting, typesetting, and review of the resulting proof before it is published in its final form. Please note that during the production process errors may be discovered which could affect the content, and all legal disclaimers that apply to the journal pertain. 


\title{
AGrav - the New International Absolute Gravity Database of $B G I$ and $B K G$ and its Benefit for the Global Geodynamics Project (GGP)
}

\author{
H. Wilmes ${ }^{\text {a }}$, H. Wziontek ${ }^{\mathrm{a}}$, R. Falk ${ }^{\mathrm{a}}, \mathrm{S}$. Bonvalot ${ }^{\mathrm{b}}$ \\ ${ }^{a}$ Bundesamt für Kartographie und Geodäsie (BKG), Richard-Strauss-Allee 11, \\ D-60598 Frankfurt a.M., Germany \\ ${ }^{\mathrm{b}}$ Bureau Gravimétrique International (BGI), Observatoire Midi-Pyrénées, \\ 14-16 Avenue Edouard Belin, F-31401 Toulouse Cedex 4, France
}

\begin{abstract}
A new database for absolute gravity (AG) measurements has been implemented at BGI and BKG and is operational now for storing absolute gravity data either in the form of metadata or as detailed measurement results. The database development was proposed by the IGFS (International Gravity Field Service) and is expected to have a great importance for the GGOS (Global Geodetic Observing System) initiative. This database will provide an overview about AG stations and observations and by this improve the cooperation between gravity groups and foster the combination with other geodetic observation techniques. The international community of absolute gravimeter users is asked to contribute to this database.
\end{abstract}

In addition to its primary purposes, demonstration of the global site distribution and information about available observations, the database could also provide an important contribution to the Global Geodynamics Project (GGP). Precise repeated absolute gravity measurements at the superconducting gravimeter (SG) sites are necessary for the determination of SG drift parameters and can be used for checking SG instrument calibration factors. The AGrav database is capable of storing the necessary AG observations at the SG location in detail up to the "single drop level" and provide this information for the combination with SG time series. An example for a selected station is presented. It is proposed to establish an interface between the AGrav and GGP databases.

Keywords. superconducting gravimeter, calibration, absolute gravimeter, absolute gravity database

\section{$1 \quad$ Introduction}

Studies of superconducting gravimeter (SG) time series for geophysical and geodetic applications require precise knowledge of the instrumental drift behaviour and the calibration parameters. Repeated absolute gravimeter (AG) measurements at the SG's location can be used to determine the SG instrumental drift function and by this enable to distinguish between instrumental drift and gravity changes caused by geophysical processes. Hinderer et al. (1991) and Francis, van Dam (2002) demonstrated that by the combination of SG time series and repeated AG measurements precise calibration factors can be determined with their uncertainty estimates. Further studies by Wziontek et al. (2009) showed that in a combined procedure SG and AG measurements can be used to determine SG drift and calibration

\footnotetext{
* corresponding author, fax: +49-69-6333425, e-mail: herbert.wilmes@bkg.bund.de
} 
together with the offset checks for the contributing absolute gravimeters. With data over a longer period offset changes for the AG e.g. after maintenance works can be detected.

Since 1993 the community of SG users has been organised in the Global Geodynamics Project (GGP) (Hinderer and Crossley, 2003) and most of their observations are stored in a common database which advances cooperation and investigations with regional and global applications.

International comparisons of absolute gravimeter are organised in four-yearly intervals at BIPM in Sevres by the „Consultative Committee for Mass and Related Quantities (CCM), Working Group on Gravimetry" and the "IAG Study Group on the Comparison of Absolute Gravimeters" (e.g. Vitushkin et al. 2002). Still, a comparable status of organisation has not yet been achieved for the community of absolute gravimeter users as concerns the cooperation in measurement projects, the harmonisation of processing standards and the sharing of observation results.

\section{Absolute Gravity Database AGrav}

The growing number of AG instruments, together with the understanding that the absolute gravity measurements have a high importance in their timely and geographical distribution, encourage the development of an international database for absolute gravity observations. This database under the umbrella of the International Gravity Field Service (IGFS) (Forsberg et al. 2005) was developed by the Bundesamt für Kartographie und Geodäsie (BKG) and put into operation together with the Bureau Gravimétrique International (BGI). This new database not only improves the propagation and notice of the AG observations and by this enhance the use of gravity data, but will also encourage cooperation in regional and global gravity projects. Work has begun to develop common standards for AG measurements and data evaluation procedures using consistent parameters and models.

The system was set into operation at two mirrored servers with web-based frontend located at BGI: http://bgi.dtp.obs-mip.fr/agrav-meta/ and at BKG: http://agrav.bkg.bund.de/agrav-meta/. Fig. 1 shows the AGrav database graphical web interface. With this realization the database pursues the following aims:

- to reach a better dissemination of information on the $\mathrm{AG}$ technique and existing observations

- to provide a means for the coordination of activities

- to facilitate cooperation between AG user groups

- to assist the combination of gravity data with other techniques

- to make the observed gravity data comparable

- to provide secure storage of AG observations for long-term availability

- to improve the scientific usability of the AG measurements.

Figure 1: Layout of the AGrav database web interface (status 2008)

The AGrav database informs about station location, observation epoch, instrument type and serial number, instrument owner or user respectively and measurement results. Accordingly, the basic structure of the relational database is composed by four tables to store information about the stations, instruments, measurement epochs, and involved institutions, which are linked to each other. Other details can be stored in supplemental tables. In this way, storage of redundant information is avoided and a flexible adaption to future needs is possible. 
Concerning observation epochs for instance, it is possible just to store time and date of the observation up to complete processing results, including single drop observations.

The database concept distinguishes two basic features:

- It can inform with meta data about measurements and, where the details are available, about results, but with limited accuracy. This service is freely available without access restrictions.

- It can store the measurement results including all corrections and processing details. Here, restrictions are applied, access is granted only to users, who have contributed own data.

By this design, meta data and detailed data share the same database. Dependent on task and authentication, meta information only or complete datasets are provided. In this way it is possible just to inform other interested groups about the existence of the stations and observations or to store the data for projects, publications and cooperation. The latter case with the complete observation results would be very helpful for cooperation between groups or if the database is used as permanent repository. In any case, the user retains control over the data, which means, later editing of submitted data is possible at any time

Stored gravity data can differ in their resolution and level of detail. To facilitate the upload of new data into the database, a format standard was chosen which is based upon the so-called "project file", a file which is generated automatically by the FG5- or A10-type gravimeter and its standard processing software "g" (Micro-g Lacoste Inc. 2007) during data taking or reprocessing. This software is applied by the majority of AG users. Due to a simple format structure, conversions can be made to include also data from other instruments and processing formats. To provide station descriptions or additional information to instruments or observations, additional documents of arbitrary format can be uploaded and linked to the primary data. Table 1 shows the information uploaded from the "project file" into the AGrav database structure.

Additional information about the processing results as, e.g. tidal models or laser frequencies, are documented in a copy of the complete project file. Information about the institution needs to be entered manually during the upload procedure.

For the proposed application only the measurements at the GGP sites are of interest. If the SG drift function is searched for, only those AG observations, which are processed consistently with respect to reduction models for tides, atmosphere and polar motion can be used.

When the calibration factor should also be determined, it is necessary to go back to the uncorrected observations with SG and AG. If data from more than one AG are included in the analysis the offset between AG instruments also needs to be determined or must be known from an earlier independent analysis.

Table 1: Content of the g-Software "Project" file transferred into the AGrav database structure

\section{The Combination of AG and SG observations}

The complementary characteristics of the superconducting gravimeter (SG), a relative sensor with low noise level of $0.1 \mathrm{~nm} / \mathrm{s}^{2}$ and very stable instrumental drift on the order of a few 
$10 \mathrm{~nm} / \mathrm{s}^{2}$ per year, and the absolute gravimeter (AG), a drift-free sensor due to its direct reference to physical standards with a measurement uncertainty of a few $10 \mathrm{~nm} / \mathrm{s}^{2}$ for single drop, lead to the development of an evaluation procedure by which observations of both instrument types at the same station are combined and SG drift parameters and calibration factors are determined in one least squares solution together with the offsets of the participating AG. Fig. 2 shows the main features of both gravimeter types and the principle of the combination procedure.

Figure 2: Features of superconducting and absolute gravimeters

In the following an example for the BKG station Bad Homburg is explained where SG-30 operated continuously from 2002 to 2006 . In parallel repeated absolute gravity measurements were performed with in total 8 instruments operated by BKG and visiting institutions. The two graphs in fig. 3 show the input data, SG residuals curve after reduction of tides, atmospheric influence and polar motion, together with the results of $175 \mathrm{AG}$ measurements after applying the same reductions. (Each AG measurement consists of at least 6 (in general 24) sets of 150 drops each every 10 seconds.) The adjustment result shows the gravity residual curve (in red) after the instrumental drift is removed and calibration is improved. The AG results could be improved further by including instrumental offsets in the range of a few $10 \mathrm{~nm} / \mathrm{s}^{2}$. Due to this relatively long comparison period with a large number of observations even smaller but significant offset changes for single AG could be detected. These changes could be related to maintenance works (Wziontek et al., 2009).

Figure 3: Example for the combination of $A G$ and $S G$ observations at the station Bad Homburg (Germany); upper graph: SG-30 residual gravity function (black) and AG measurement results of $8 \mathrm{AG}$, symbols in selected colours; lower graph: SG and AG observations prior (black/upper curve) and after combination (red/lower curve); AG measurement results show smaller residuals after offset determination for the individual AG.

\section{Benefit for the GGP community}

Which role can the AG database AGrav play for the GGP? AGrav is an operational database in which AG measurements can be stored with the required resolution. With contributions from the AG community the data could be used by the members of GGP to link this information to the SG time series. Apart from the more simple approach of using one absolute gravity value per occupation with the $A G$, it is also possible to extend the comparison between both instrument types to the AG single drop level. This enables more detailed investigations of the SG calibration factor and the uncertainty of the combination of both measurement series.

The next necessary steps for the adaptation of the AGrav database to the proposed GGP application would be to implement a user interface for the upload of AG drop data for the AG community and a similar interface for the SG community to retrieve these data for a selected SG site. 
A direct cooperation between the SG and $\mathrm{AG}$ communities is proposed which includes the link of the two databases, GGP and AGrav. The benefit would be the possibility to determine SG drift and calibration parameters and by this to create a combined verified gravity signal. The AGrav database foresees the storing of AG occupation results and AG drop data at the sites of the GGP network. For the successful combination of both data types it is necessary to ensure consistent AG gravity measurements together with agreed standards for the analysis of both types of gravity data. In addition it will be necessary to adapt the AGrav database with an additional interface which supports the upload and retrieval of single drop AG measurements.

\section{References}

Bonvalot, S., 2007. International Gravimetric Bureau (Bureau Gravimétriques International BGI). International Association of Geodesy, IAG Handbook 2008 (Internet Version), Geodesist's Handbook, http://iag.dgfi.badw.de/fileadmin/handbook/3-5-11-bgi.pdf .

Forsberg, R., Sideris, M.G., Shum, C.K., 2005. The gravity field and GGOS, Journal of Geodynamics, 40 (4), 387-393.

Francis O. and van Dam T., 2002. Evaluation of the precision of using absolute gravimeters to calibrate superconducting gravimeters, Metrologia 39, 485-488.

Hinderer, J., N. Florsch, J. Mäkinen, H. Legros, J.E. Faller, 1991. On the calibration of a superconducting gravimeter using absolute gravity measurements. Geophys. J. Int. 106, 491-497.

Hinderer, J. and Crossley, D., 2004. Scientific achievements from the first period (1997-2003) of the Global Geodynamics Project using a worldwide network of superconducting gravimeters, Journal of Geodynamics, Vol. 38, Issues 3-5, 237-262.

Micro-g Lacoste Inc., 2007. g7 Absolute Gravity Data Acquisition and Processing Software, g7 User's Manual, http://www.microglacoste.com/pdf/g7Help.pdf.

Vitushkin, L., M. Becker, Z. Jiang, O. Francis, T.M. van Dam, J. Faller, J.-M. Chartier, M. Amalvict, S. Bonvalot, N. Debeglia, S. Desogus, M. Diament, F. Dupont, R. Falk, G. Gabalda, C.G.L. Gagnon, T. Gattacceca, A. Germak, J. Hinderer, O. Jamet, G. Jeffries, R. Käker, A. Kopaev, J. Liard, A. Lindau, L. Longuevergne, B. Luck, E.N. Maderal, J. Mäkinen, B. Meurers, S. Mizushima, J. Mrlina, D. Newell, C. Origlia, E.R. Pujol, A. Reinhold, Ph. Richard, I.A. Robinson, D. Ruess, S. Thies, M. Van Camp, M. Van Ruymbeke, M.F. de Villalta Compagni and S. Williams, 2002. Results of the Sixth International Comparison of Absolute Gravimeters, ICAG-2001, Metrologia 39, 407-424.

Wziontek, H., Falk, R., Wilmes, H., Wolf, P., 2009. Precise gravity time series and instrumental properties from combination of superconducting and absolute gravity measurements. In: Sideris, M. (Ed.), Observing our Changing Earth. Vol. 133 of International Association of Geodesy Symposia. Springer, Berlin Heidelberg, 301-306. 
Figure 1: Layout of the AGrav database web interface (status 2008)

Figure 2: Features of superconducting and absolute gravimeters

Figure 3: Example for the combination of $\mathrm{AG}$ and $\mathrm{SG}$ observations at the station Bad Homburg (Germany); upper graph: SG-30 residual gravity function (black) and AG measurement results of $8 \mathrm{AG}$, symbols in selected colours; lower graph: SG and AG observations prior (black/upper curve) and after combination (red/lower curve); AG measurement results show smaller residuals after offset determination for the individual AG.

Table 1: Content of the g-Software "Project" file transferred into the AGrav database structure 


\section{Figure 1}

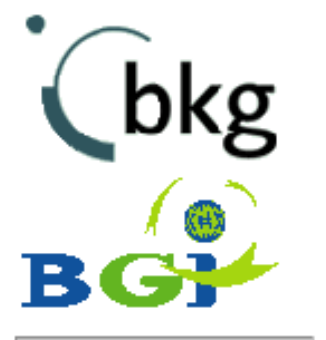

Map

Meters

Stations

Observations

Institutions

Full Access

(loqin required)

Bifirror at BGI

agrav@bkg.bund.de

bqi@cnes.fr
AGrav: Absolute Gravity Database - Meta-Data

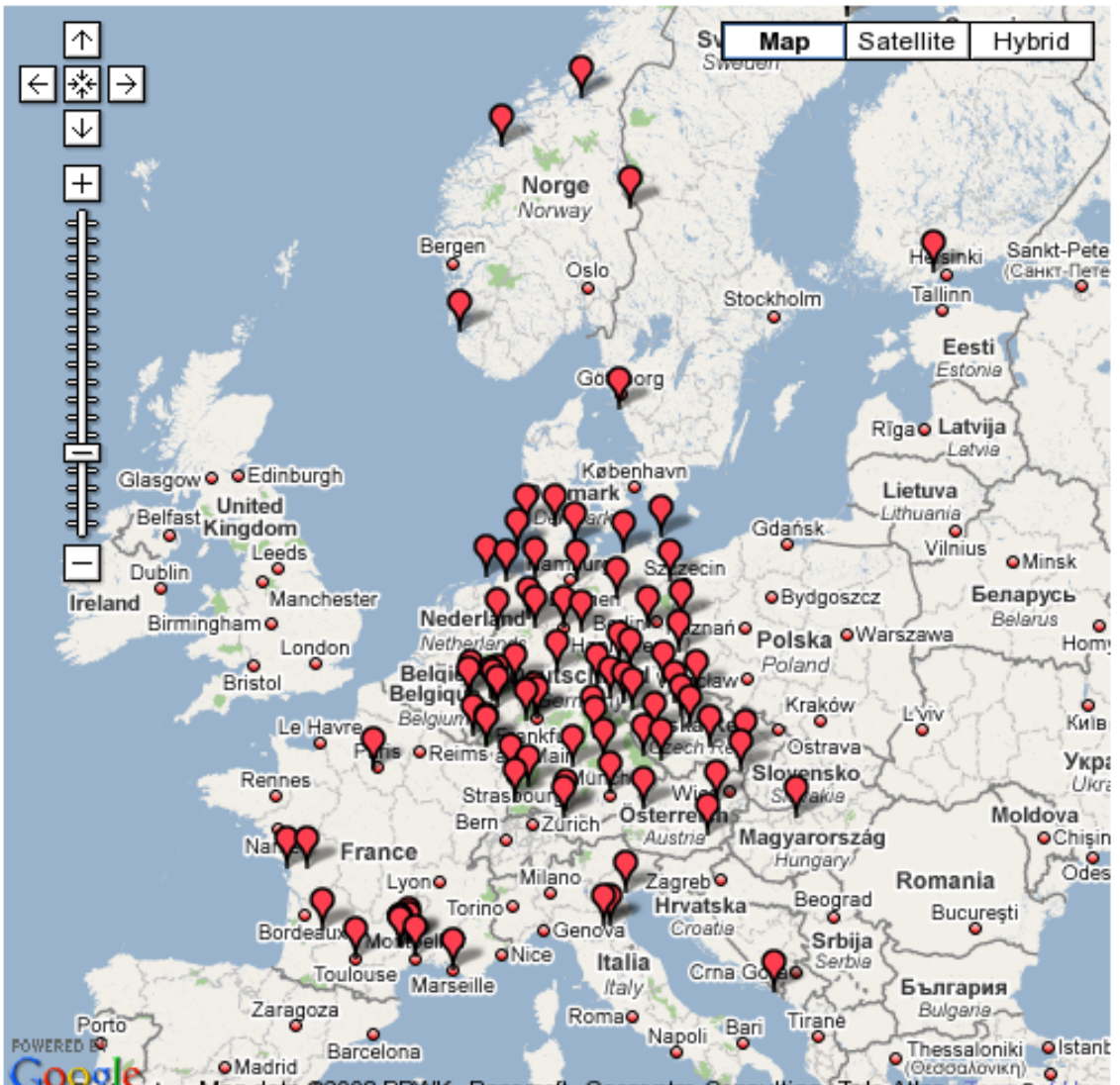

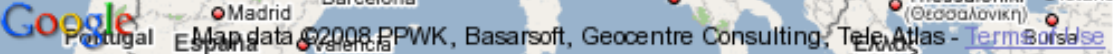


Figure 2

\section{Complementary instrumental characteristics}

Superconducting Gravimeter (SG)

Absolute Gravimeter (AG)
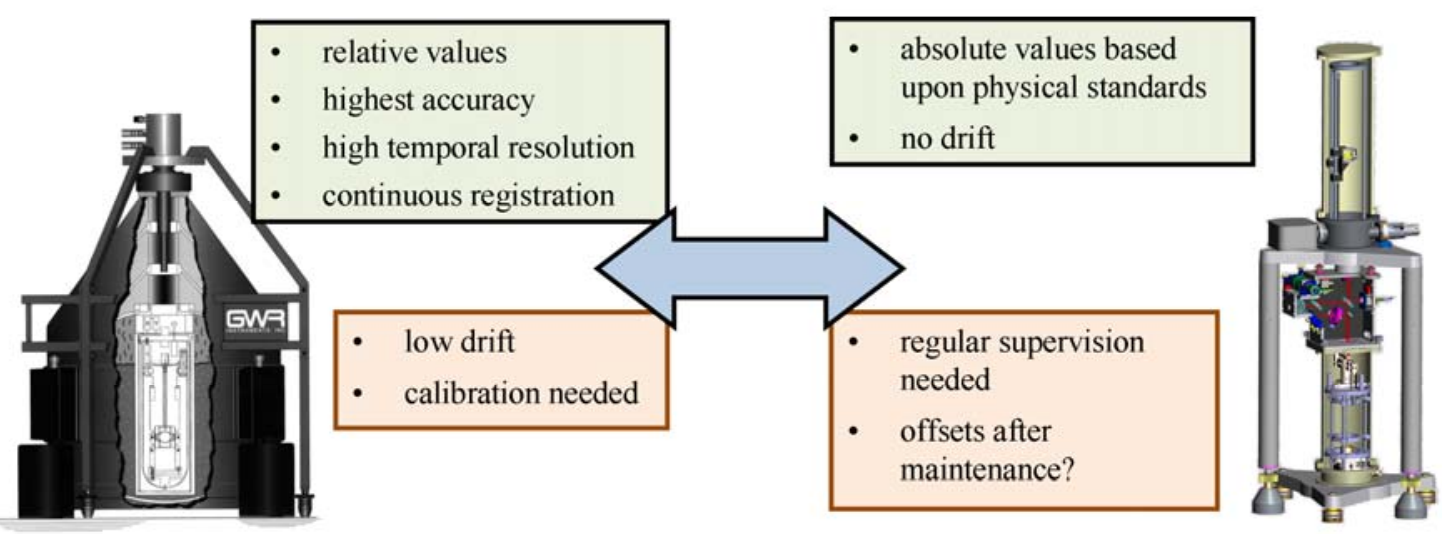
Figure 3

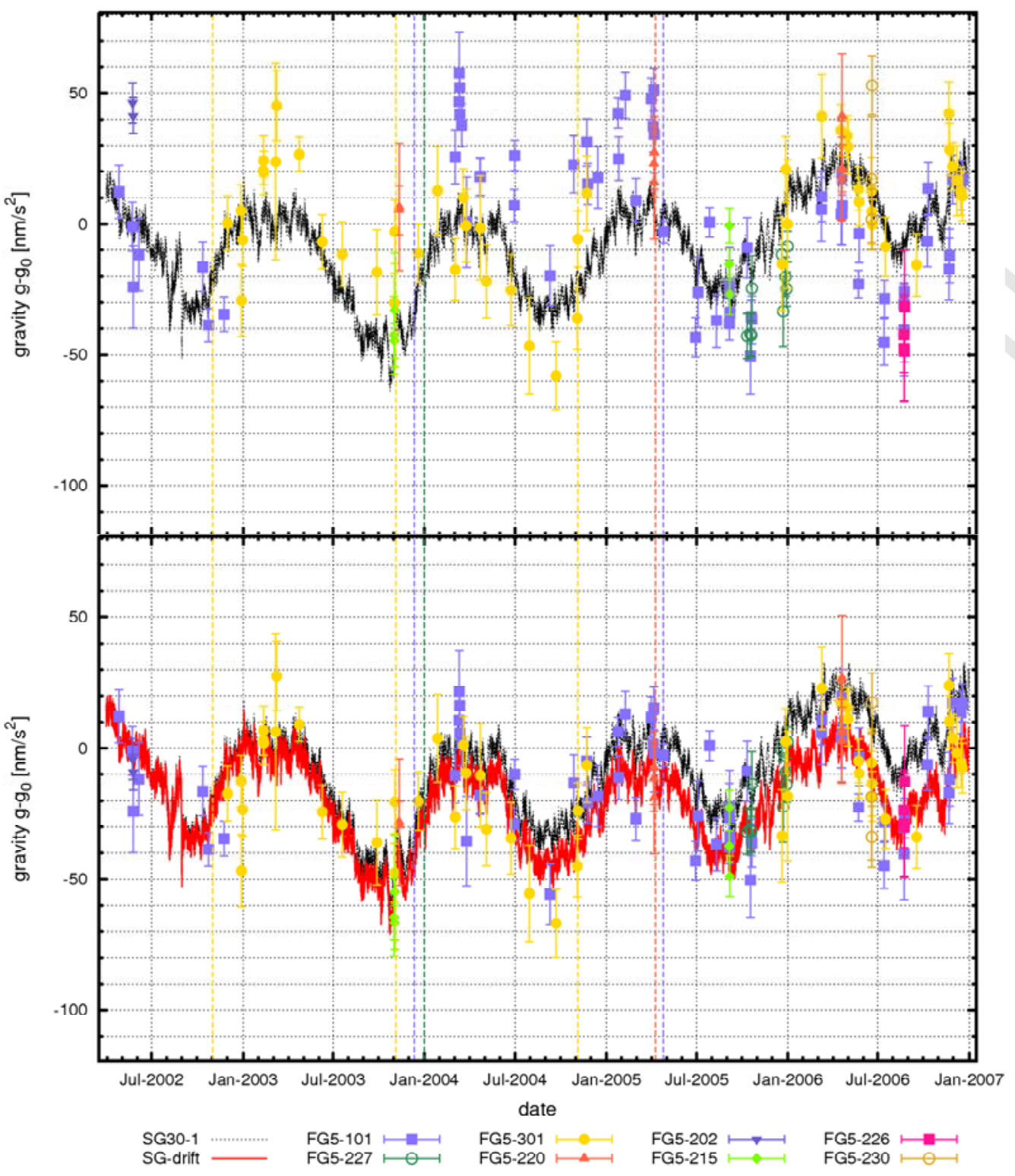


Table 1: Content of the g-Software "Project" file transferred into the AGrav database structure

\begin{tabular}{|l|l|}
\hline Station & Name \\
Information & Site Code \\
& Longitude \\
& Latitude \\
& Height \\
\hline Instrument & Meter Type \\
Information & Meter Serial \\
\hline Observation & Reference Date/Time \\
Epoch & Gravity \\
& Total Uncertainty \\
& Measurement Precision \\
& Transfer Height \\
& Laser \\
& Number of Sets Collected \\
& Number of Drops per Set \\
& Operator \\
& *ot updated automatically \\
\hline Processing & Processing Date/Time \\
& Project Name \\
& Gravity \\
& Set Scatter \\
& Measurement Precision \\
& Total Uncertainty \\
Acquisition Version \\
& Processing Version \\
Setup Height \\
Transfer Height \\
Factory Height \\
Gradient \\
& Barometric Admittance Factor \\
& Polar Motion Coordinates \\
Nominal Air Pressure \\
Fringe Start \\
Processed Fringes \\
Rubidium Frequency \\
Modulation Frequency \\
\hline
\end{tabular}

